\title{
Exportadores brasileiros: estudo exploratório das percepções sobre a qualidade da infraestrutura logística
}

\author{
Peter Fernandes Wanke UFRJ \\ Maria Fernanda Hijjar UFRJ
}

\section{RESUMO}

O objetivo desta pesquisa é avaliar as percepções de diferentes segmentos de exportadores sobre a qualidade da infraestrutura logística de exportação. Para isto, foram definidas e operacionalizadas, com base na revisão de literatura, as principais dimensões de segmentação de exportadores: tipo de carga (contêiner ou granel) e criticidade da operação portuária. Foram enviados questionários para os 250 maiores exportadores brasileiros do ranking da AEB (Associação de Exportadores Brasileiros). A partir dos 101 questionários recebidos foi possível identificar que exportadores de carga a granel tendem a considerar o escoamento e o acesso aos portos uma dificuldade logística mais crítica que os exportadores de cargas em contêineres. Já com relação à criticidade da operação porto-a-porto, os exportadores do setor de insumos industriais percebem a piora da qualidade da infraestrutura física do modal marítimo e da burocracia para exportação como reflexo de limitações na sua capacidade de produção.

PALAVRAS-CHAVE

Exportadores, qualidade, infraestrutura, logística.

\section{Brazilian exporters: exploratory study on the perceptions about logistics infrastructure quality}

\begin{abstract}
The objective of this research is to evaluate the perceptions of different trading firms about the quality of the logistics infrastructure for the foreign trade. Based on the literature review, the major dimensions regarding these firms were defined and operationalized: type of load (container or bulk) and criticality of port operation. A survey was conducted with the 250 largest Brazilian firms ranked at the AEB list (Brazilian Foreign Trade Firms Association). Based on the 101 questionnaires returned, it was identified that the bulk traders tend to consider the access to ports a bigger logistical shortcoming than the container traders. With regard to the criticality of port operation, firms of the intermediate goods industry perceive the decay of the physical infrastructure and the foreign trade bureaucracy as a consequence of their limited production capacity.
\end{abstract}

\section{KEY WORDS}

Foreign trade firms, quality, infrastructure, logistics. 


\section{INTRODUÇÃO}

A importância da infraestrutura logística para as economias nacionais e para as empresas tem aumentado fortemente nos últimos anos (CULLINANE et al., 2005). De forma a apoiar o crescimento econômico com base nas exportações, os governos do mundo todo têm estado constantemente sob pressão para melhorar a qualidade de infraestrutura logística, assegurando que as empresas usuárias de seus serviços sejam competitivas internacionalmente. É consenso que a infraestrutura logística forma um elo vital na cadeia total de comércio, contribuindo para a competitividade internacional de um país (TONGZON, 1989; CHIN; TONGZON, 1998).

No Brasil, um dos chamados "países emergentes" ou "BRICs" (WILSON; PURUSHOTHAMAN, 2003), as exportações mais que dobraram no período compreendido entre 2002 e 2007, alcançando quase US\$ 160 bilhões (FLEURY; HIJJAR, 2008). Quase metade desse volume está concentrada em commodities "cruas" e commodities com pequeno grau de beneficiamento industrial (soja em grão, minério de ferro, petróleo cru, suco de laranja congelado, petroquímicos, café, açúcar, etanol, celulose etc.) e a outra metade se deve à exportação de produtos manufaturados (carne processada, automóveis, aço, aviões, eletrodomésticos e autopeças). ao Ministério dos Transportes foi criada para monitorar os gargalos operacionais e alocar os investimentos entre os portos e terminais brasileiros (Secretaria dos Portos). Nesse ambiente, a mensuração da infraestrutura não é apenas uma poderosa ferramenta gerencial para as autoridades, mas também constitui um dos mais importantes insumos para planejamento regional e nacional das operações de comércio internacional.

No entanto, deve ser destacado que, na grande maioria das vezes, o debate sobre a infraestrutura logística de exportação, suas restrições e seus impactos em termos de ineficiências operacionais, é conduzido em termos genéricos e desconsidera as eventuais especificidades dos diferentes segmentos exportadores, bem como suas diferentes percepções sobre o problema. Mais especificamente, é provável que diferentes segmentos exportadores percebam a qualidade da infraestrutura logística de forma diferente. São diversas as evidências empíricas de que diferentes setores da economia percebem os problemas da qualidade de infraestrutura de forma diferente e em diferentes pontos da cadeia, por exemplo, nos portos e/ou nas ferrovias (TORRES, 2004a, 2004b; GAZETA MERCANTIL, 2004; SALES, 2001; SOUZA, 2004).

Além disso, é provável que a incipiência da discussão sobre a percepção da qualidade da infraestrutura logística no Brasil à luz da segmentação dos exportadores seja causada fundamentalmente pela falta de um entendimento mais claro sobre as principais dificuldades logísticas à exportação e sua importância relativa para os diferentes segmentos exportadores. Burocracia (RIOS, 2004a), disponibilidade de infraestrutura física (RIOS, 2004b), restrições de acesso, filas (NÓRCIO; PIMENTEL, 2004) e/ou frequência e disponibilidade de rotas (PORTOS E NAVIOS, 2004), constituem alguns exemplos de dificuldades logísticas à exportação que podem afetar as percepções sobre a qualidade da infraestrutura logística de exportação.

Dessa forma, este artigo tem por objetivo analisar a percepção de diferentes segmentos exportadores brasileiros sobre a qualidade da infraestrutura logística. Em primeiro lugar, através da identificação e validação das principais dimensões de segmentação dos exportadores, com base na revisão de literatura e no melhor entendimento das principais dificuldades à exportação. Em segundo lugar, através da identificação e mensuração das diferentes dimensões componentes da infraestrutura logística de exportação em termos de suas percepções de qualidade. 


\section{DIMENSÕES DE SEGMENTAÇÃO DOS EXPORTADORES}

Conforme indicado, a discussão sobre a segmentação dos exportadores é insipiente na literatura. Algumas dimensões como tipo de carga (contêiner ou granel) e a percepção do exportador com relação à criticidade da operação portuária parecem ser relevantes.

Por exemplo, Clark et al. (2004) investigaram as variáveis determinantes da eficiência nas exportações (gastos com transporte), dado certo nível de infraestrutura. Distâncias, volumes, características do produto e tipo de carga são as principais variáveis que afetam essa relação. No Brasil, Wanke et al. (2008) identificaram que o tipo de carga movimentado (contêiner ou granel) afeta diretamente o nível de eficiência dos portos. Já que exportadores de diferentes tipos de carga experimentam gastos com transportes diferentes, bem como níveis de eficiência diferentes, é possível que também percebam a qualidade da infraestrutura de modo diferente.

Por outro lado, em alguns casos, parece que a criticidade da operação portuária é uma importante variável para a tomada de decisão. Walter e Poist (2004) apontam que para exportadores de estados internos (não-litorâneos) como Iowa, há uma clara preferência por portos secos do tipo "one-stop-shopping", onde são realizados, antecipadamente, todos os tipos de serviço de desembaraço aduaneiro e montagem de carga, representando ganho de tempo em relação aos portos tradicionais. A criticidade da operação portuária parece ser influenciada pelas dificuldades logísticas de acesso de estados internos dos EUA, como Iowa. No Brasil, as Estações Aduaneiras de Interior (EADIs) constituem iniciativa semelhante (RECEITA FEDERAL, 2004). Entretanto, não é possível determinar a priori, quais outras características dos exportadores levariam a uma maior criticidade da operação portuária. O máximo que pode ser afirmado é que as dificuldades logísticas à exportação, de modo geral, parecem estar relacionadas a essa dimensão.

Finalmente, outra dimensão de segmentação relevante estaria associada ao tipo de indústria do exportador e à sua estrutura do processo produtivo. Wanke et al. (2007) identificaram que diferentes estruturas do processo produtivo (V, A ou T, conforme proposta de CHASE; AQUILANO, 1992), bem como diferentes setores industriais (bens de consumo duráveis, não-duráveis e insumos intermediários) levam à contratação de operadores logísticos com diferentes perfis: funcionais ou integradores. É possível que essas dife- renças também se manifestem em necessidades específicas com relação à infraestrutura de exportação, afetando as percepções sobre sua qualidade.

\section{INFRAESTRUTURA DE EXPORTAÇÃO E PRINCIPAIS DIMENSÕES DE ANÁLISE}

O impacto da infraestrutura logística nas exportações é amplamente reconhecido em todo mundo (LIMÃO; VENABLES, 2001). De todos os custos logísticos, os gastos de transporte são comprovadamente afetados pelo nível de infraestrutura (MARTINEZ-ZARZOSO et al., 2003). Além

\section{$\Delta$ s escalas ordinais mostram-se bastante úteis para operacionalizar percepções e aspectos subjetivos junto aos entrevistados.}

do frete, os gastos com transporte na exportação também envolvem outros itens, como demurrage de navios, detention de contêineres, diárias de caminhões e diárias de trens, todos associados a penalidades decorrentes por sobrestada e ociosidade desses ativos. De acordo com a pesquisa de Limão e Venables (2001), "a deterioração da infraestrutura da mediana para o percentil 75 aumenta os gastos com transporte em doze pontos percentuais e reduz o volume de comércio em $28 \%$ ". No debate brasileiro sobre a infraestrutura logística de exportação, esses itens de gasto são frequentemente denominados de Custo Brasil (FIGUEIREDO et al., 2003).

A acumulação de infraestrutura, todavia, é limitada por uma determinada fronteira tecnológica e inclui componentes fixos e variáveis (BOUGHEAS et al., 2004).

Componentes fixos envolvem a infraestrutura física, ou seja, em sentido amplo, os modais de transporte pelos quais são escoados os carregamentos. A exportação é uma operação multimodal por natureza, com os carregamentos sendo transportados por rodovias, ferrovias e hidrovias até os pontos de saída, ou seja, portos e aeroportos. Os modais por sua vez estão fortemente associados à formação dos custos de transporte e ao uso racional de uma alternativa em detrimento de outra. Wanke e Fleury (2006) avaliaram a necessidade de segmentar o transporte de cargas com base nos custos dos diferentes modais, buscando uma adequação do tipo de carga e do tipo de rota ao tipo de modal. Uma eventual distorção nessa adequação poderia afetar como a qualidade da infraestrutura logística é percebida pelo exportador, visto que ele estaria 
sendo condicionado a utilizar um modal menos adequado ao seu tipo de operação.

Já os componentes variáveis envolvem a infraestrutura burocrática, ou seja, legislação, impostos, taxas, procedimentos aduaneiros de despacho de carregamentos e eventuais facilidades. No Brasil, merecem destaque cada vez maior as EADIs (GUIA DE LOGÍSTICA, 2004), ou seja, as Estações Aduaneiras de Interior. As EADIs são recintos alfandegados de uso público, situados em zona secundária, nos quais são executadas, em regime de concessão, as operações de movimentação, armazenagem e despacho aduaneiro de mercadorias. A prestação desses serviços aduaneiros em porto seco próximo ao domicílio dos exportadores proporciona uma grande simplificação de procedimentos (RECEITA FEDERAL, 2004). tadores brasileiros, com base nos fatores identificados na primeira questão.

Pergunta 3: Quais são os grupos de exportadores formados a partir de semelhanças nos diferentes fatores associados às dificuldades logísticas para a exportação?

Por sua vez, a quarta pergunta está relacionada à caracterização da dimensão de segmentação e, consequentemente, dos grupos identificados na terceira questão.

Pergunta 4: Quais são os setores da economia e as estruturas dos processos produtivos representativos dos grupos formados com base em semelhanças nas dificuldades logísticas para exportação?

Finalmente, a quinta e última pergunta está relacionada à determinação de relações entre as variáveis das diferentes dimensões de percepção da qualidade da infraestrutura com os principais critérios de segmentação dos exportadores identificados nas questões anteriores.

\section{percepções sobre os diferentes aspectos} relacionados à infraestrutura de exportação.

\section{PRINCIPAIS PERGUNTAS E METODOLOGIA DE PESQUISA}

Com base na discussão anterior, foram formuladas as cinco principais perguntas da pesquisa. A primeira pergunta está relacionada à identificação, a partir de dados empíricos, dos principais fatores associados às dificuldades logísticas para exportação. A pergunta é formalizada a seguir.

Pergunta 1: Quais os diferentes fatores associados às dificuldades logísticas para exportação, extraídos a partir de variáveis que refletem a percepção dos exportadores sobre aspectos como infraestrutura física, burocracia, Custo Brasil, disponibilidade e frequência de rotas marítimas e aéreas para o exterior, condições de armazenagem etc?

A segunda pergunta está relacionada à validação do tipo de carga (contêiner/granel) como dimensão de segmentação dos exportadores brasileiros, tendo como base os fatores identificados na primeira questão. Ela é apresentada a seguir:

Pergunta 2: Quais fatores são considerados mais críticos pelos exportadores de carga a granel e em contêineres?

Já a terceira pergunta está relacionada à identificação de outras dimensões relevantes para a segmentação dos expor-
Pergunta 5: Exportadores de diferentes segmentos apresentam diferentes percepções sobre a qualidade da eficiência operacional (filas, Custo Brasil) e da infraestrutura logística (infraestrutura física, infraestrutura burocrática, Custo Brasil e utilização de EADIs) em suas diferentes dimensões?

A estrutura conceitual que resume os objetivos dessa pesquisa é apresentada de forma esquemática na Figura 1.

Foram selecionados, a partir do ranking da Associação dos Exportadores Brasileiros (AEB), os 250 maiores exportadores em volume financeiro. Durante o segundo semestre de 2004, gerentes de logística dessas empresas foram contatados, sendo que 101 destinatários retornaram os questionários. Isto perfaz uma taxa de resposta de $40,4 \%$ com relação aos questionários inicialmente enviados.

Com relação à primeira pergunta da pesquisa, foram investigadas vinte e seis variáveis possivelmente relacionadas às dificuldades logísticas para a exportação, ou seja, relacionadas à criticidade de diferentes aspectos como infraestrutura, burocracia, Custo Brasil, disponibilidade e frequência de rotas marítimas e aéreas para o exterior, condições de armazenagem etc. Estas variáveis, sua operacionalização e suas escalas são apresentadas na Tabela 1.

Para a identificação dos principais fatores associados às dificuldades logísticas para a exportação foi utilizada a técnica de Análise Fatorial nestas vinte e seis variáveis. A Análise Fatorial é recomendada para os casos nos quais se deseja determinar diferentes fatores ou dimensões a partir das variáveis observadas, tendo como base um construto 
teórico. Neste caso, o construto teórico é composto pelas dificuldades logísticas à exportação (MALHOTRA, 2001).

Com relação à segunda pergunta da pesquisa, foi utilizada Análise de Regressão Logística Simples para relacionar os principais fatores associados às dificuldades logísticas para exportação - determinados por Análise Fatorial - com o tipo de carga (granel/contêiner). A Análise de Regressão Logística Simples é preferível à Análise Discriminante na separação de dois grupos de dados (tipo de carga) em função de determinados critérios (dificuldades logísticas à exportação), por sua menor rigidez com relação à necessidade da normalidade das matrizes de variância e covariância dos dados (HAIR et al., 1998). Sua utilização e interpretação são bastante intuitivas e análogas à Análise de Regressão Linear Simples (KLEINBAUM et al., 1998) e não há necessidade de assegurar a normalidade das matrizes de covariância dos dados, assim como ocorre na Análise Discriminante (HAIR et al., 1998).

Por sua vez, com relação à terceira pergunta da pesquisa, foi utilizada a técnica de Análise de Cluster nos 101 exportadores pesquisados (FIELD, 2005). Em função do caráter exploratório do estudo, estes exportadores foram subdivididos em apenas dois grupos para permitir melhor interpretação dos resultados, dado o caráter exploratório da pesquisa (MALHOTRA, 2001).

Já com relação à quarta pergunta da pesquisa, foram utilizadas técnicas univariadas, como a Análise de Correlação Não Paramétrica, para relacionar os dois grupos definidos pela Análise de Cluster às percepções sobre diferentes aspectos da eficiência operacional na exportação; e multivariadas, como a Análise de Regressão Logística Simples, para relacionar esses grupos com o setor da economia e a estrutura do processo produtivo. Estas variáveis, sua operacionalização e suas escalas são apresentadas na Tabela 2.

Por fim, com relação à quinta pergunta, foram utilizadas duas diferentes técnicas multivariadas para relacionar as diferentes dimensões de percepção da qualidade da infraestrutura com os principais critérios de segmentação dos exportadores: Análise de Regressão Ordinal e Análise de Regressão Múltipla. Deve ser destacado que a escolha dos métodos estatísticos empregados, para relacionar essas diferentes dimensões de percepção aos critérios de segmentação, observou a natureza de suas escalas. Castro (1978) aponta para a crucial importância da compatibilidade entre as escalas das variáveis dependentes e as análises estatísticas.

Evidências empíricas coletadas na imprensa

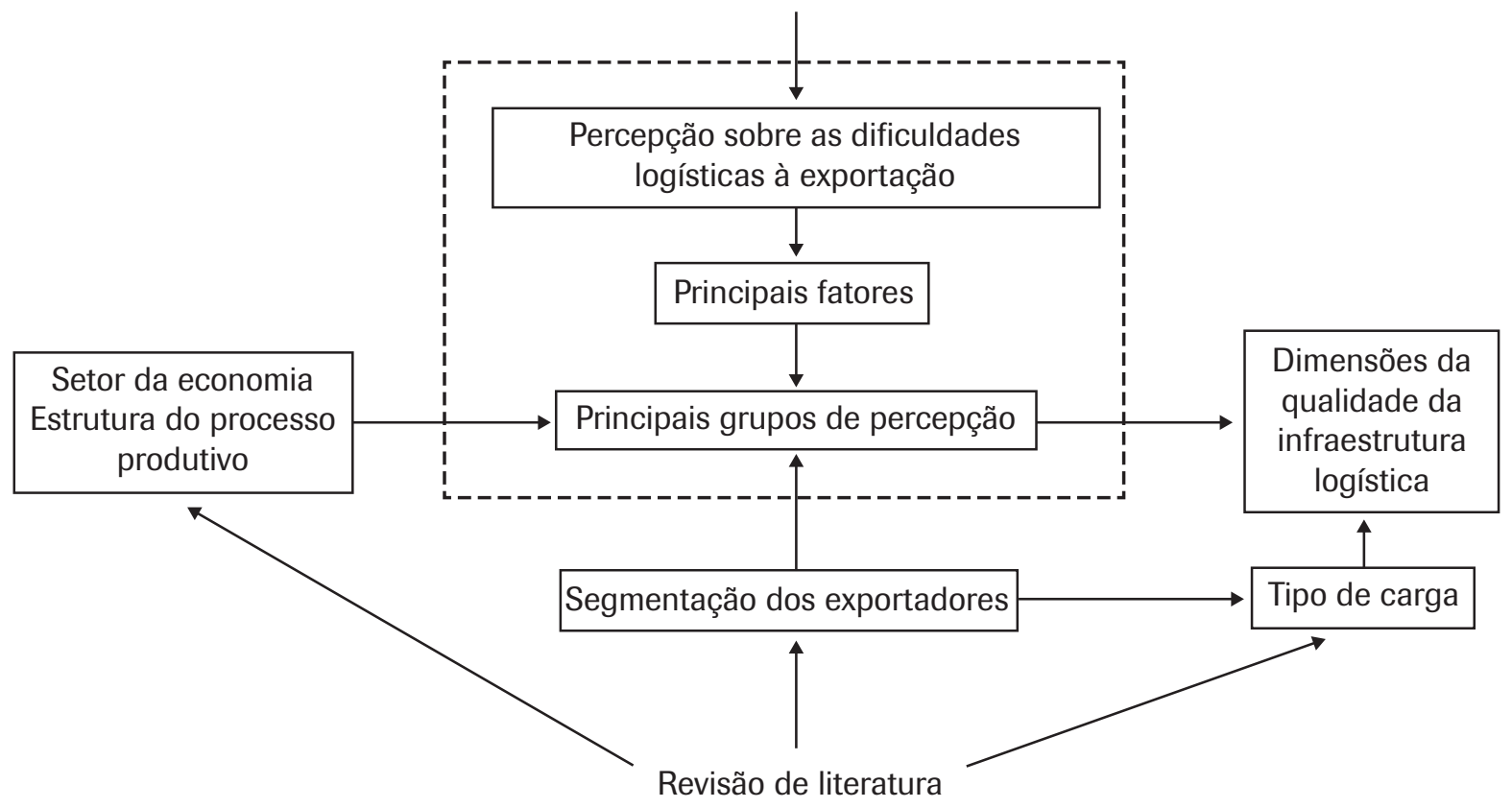

Figura 1: Estrutura conceitual da pesquisa. 
Estas variáveis, sua operacionalização e suas escalas são apresentadas na Tabela 2.

Especificamente com relação às escalas adotadas e apresentadas nas Tabelas 1 e 2, optou-se sempre que possível por uma escala Likert de cinco pontos ou categorias (MALHOTRA, 2001), comumente adotada em pesquisas em logística (MENTZER; FLINT, 1997). A escala Likert é um tipo de escala ordinal, apresentando, portanto, propriedades de variáveis discretas (TABACHNIK; FIDELL, 2001). Uma limitação, talvez discutível, associada ao uso de escalas ordinais, é a quantidade de informação fornecida pela magnitude das diferenças entre as diferentes categorias (KLEINBAUM et al., 1998). Mesmo assim, as escalas ordinais mostram-se bastante úteis para operacionalizar percepções e aspectos subjetivos junto aos entrevistados, auxiliando na codificação de respostas em relação às quais seria extremamente custoso levantar as informações (MALHOTRA, 2001).

O processo de construção de definições formais sobre os conceitos inerentes à teoria em questão resulta nas escalas de mensuração. A validação de escalas é um processo complexo, composto por diferentes dimensões que objetivam assegurar a correta definição e mensuração do fenômeno teórico em estudo (MENTZER; FLINT, 1997). A avaliação de escalas num projeto de pesquisa deve observar se as escalas escolhidas representam métricas adequadas aos conceitos formalizados com base na teoria. Os principais componentes envolvidos na validação de escalas seriam: validade nomológica, validade de conteúdo, validade de convergência, validade discriminante e confiabilidade (DUNN et al., 1994; GARVER; MENTZER, 1999).

A validade nomológica envolve o grau de aderência de uma escala na rede de encadeamentos lógicos da teoria, constituindo-se numa medida da correspondência teórica entre o conceito e a escala. Por sua vez, a validade de conteúdo seria uma medida de quão bem o significado de um conceito (contido no arcabouço teórico) é capturado por uma escala. Não existem testes estatísticos para a validação nomológica e de conteúdo, que são estritamente qualitativas e cujas relevâncias transcendem o método de pesquisa adotado.

A validade de convergência deve ser observada quando existem diferentes escalas para avaliar um mesmo conceito. Neste caso, todas as escalas devem estar relacionadas entre si, convergindo estatisticamente para um fator comum, o

Tabela 1: Variáveis relacionadas às dificuldades logísticas para exportação.

\begin{tabular}{|c|c|c|}
\hline Variáveis Pesquisadas & Escala Adotada & Tipo de Escala \\
\hline $\begin{array}{l}1 \text { - Infraestrutura rodoviária de escoamento } \\
2 \text { - Infraestrutura ferroviária de escoamento } \\
3 \text { - Infraestrutura hidroviária de escoamento } \\
4 \text { - Infraestrutura portuária de escoamento } \\
5 \text { - Infraestrutura aeroportuária de escoamento } \\
6 \text { - Infraestrutura de intermodalidade } \\
7 \text { - Burocracia } \\
8 \text { - Financiamentos do governo } \\
9 \text { - Legislação tributária } \\
10 \text { - Receita Federal - horário de funcionamento } \\
11 \text { - Tempo de liberação de mercadorias } \\
12 \text { - Greves } \\
13 \text { - Custos rodoviários de transporte nacional - escoamento interno } \\
14 \text { - Preço do frete internacional } \\
15 \text { - Disponibilidade de rotas internacionais de navios } \\
16 \text { - Disponibilidade de rotas internacionais de aviões } \\
17 \text { - Frequência de navios } \\
18 \text { - Frequência de aviões } \\
19 \text { - Falta de contêineres } \\
20 \text { - Disponibilidade de armazenagem nos portos brasileiros } \\
21 \text { - Acesso aos portos brasileiros } \\
22 \text { - Filas nos portos brasileiros } \\
23 \text { - Deficiências das EADls } \\
24 \text { - Dificuldades nas fronteiras terrestres } \\
25 \text { - Deficiências dos portos nos países importadores } \\
26 \text { - Distribuição nos países importadores }\end{array}$ & $\begin{array}{l}5=\text { É problema crítico } \\
4=\text { É grande problema } \\
3=\text { É problema } \\
2=\text { É pequeno problema } \\
1=\text { Não é problema }\end{array}$ & Ordinal \\
\hline
\end{tabular}


que é o caso das percepções sobre as dificuldades logísticas à exportação, testado por Análise Fatorial. Já a validade discriminante observa se uma única escala está relacionada com diferentes estados distinguíveis dentro de um conceito, sendo esse o caso relacionado à mensuração de como as percepções podem variar por diferentes segmentos exportadores. Esse aspecto da validação é testado pela Análise de Cluster e as diferentes Análises de Regressão descritas anteriormente. Finalmente, a confiabilidade é definida como o quão consistentemente as escalas utilizadas produzem os mesmos resultados ao longo do tempo em diversas replicações do estudo por outros pesquisadores. Esse último componente da validação depende, portanto, do tempo.

A validação de escalas assume dois caminhos metodologicamente distintos quando é considerada a natureza do conceito ou da variável que se deseja medir. Se o conceito ou variável em estudo é passível de observação direta e de definição através de uma escala de razão unidimensional, a va- lidade nomológica e a de conteúdo são as componentes mais críticas para a validação da escala, podendo ser descartadas a validade de convergência, a discriminante e a confiabilidade (MENTZER; FLINT, 1997; GARVER; MENTZER, 1999). Exemplos neste sentido seriam de variáveis operacionais ou caracterizadoras da operação, como distâncias, tempos, gastos, volumes e quantidades.

Por outro lado, conceitos ou variáveis latentes definidas e mensuradas através de escalas nominais, ordinais ou cardinais, como percepções sobre a qualidade de serviço e desempenho do serviço logístico, necessitam a avaliação de todos os componentes citados anteriormente para validação de escalas. Isto porque, conforme apontam Moser e Kalton (1971), "existem praticamente infinitas maneiras possíveis de se construírem escalas para mensuração de atitudes (variáveis latentes)", contrariamente à relação unívoca entre escala e conceito, no caso das variáveis passíveis de observação direta.

Tabela 2: Variáveis relacionadas à percepção da eficiência operacional, da qualidade da infraestrutura logística e à caracterização dos exportadores.

\begin{tabular}{|c|c|c|c|c|}
\hline & Dimensão & Variáveis Pesquisadas & Escala Adotada & $\begin{array}{l}\text { Tipo de } \\
\text { Escala }\end{array}$ \\
\hline \multirow{7}{*}{$\begin{array}{l}\text { Quarta } \\
\text { Pergunta }\end{array}$} & \multirow[t]{2}{*}{$\begin{array}{l}\text { Caracterização dos } \\
\text { Exportadores: Setor da } \\
\text { Economia e Estrutura } \\
\text { do Processo Produtivo }\end{array}$} & 1 - Setor da Economia & $\begin{array}{l}1=\text { Insumos industriais } / \\
\text { produtos intermediários } \\
2=\text { Bens duráveis } \\
3=\text { Bens não-duráveis } \\
4=\text { Outros }\end{array}$ & Nominal \\
\hline & & 2 - Estrutura do Processo Produtivo & $\begin{array}{l}1=\text { Tipo } \mathrm{T} \\
2=\text { Tipo } \mathrm{V} \\
3=\text { Tipo } \mathrm{A} \\
4=\text { Outro tipo/não se aplica }\end{array}$ & Nominal \\
\hline & \multirow{5}{*}{$\begin{array}{l}\text { Caracterização } \\
\text { dos Exportadores: } \\
\text { Eficiência Operacional } \\
\text { na Exportação }\end{array}$} & 3 - Limitação da capacidade produtiva & $\%$ da capacidade & Razão \\
\hline & & 4 - Percentual estimado de perda de produtos & $\%$ de perdas & Razão \\
\hline & & 5 - Tempo de liberação no porto & $\begin{array}{l}5=\text { Bem rápido } \\
4=\text { Rápido } \\
3=\text { Adequado } \\
2=\text { Lento } \\
1=\text { Muito lento }\end{array}$ & Ordinal \\
\hline & & $\begin{array}{l}6 \text { - Impacto do Custo Brasil } \\
\text { nas margens de lucro }\end{array}$ & $\begin{array}{l}5=\text { Afetam muito } \\
4=\text { Afetam razoavelmente } \\
3=\text { Afetam pouco } \\
2=\text { Afetam marginalmente } \\
1=\text { Não afetam }\end{array}$ & Ordinal \\
\hline & & $\begin{array}{l}7 \text { - Contratação de operador } \\
\text { logístico global }\end{array}$ & $\begin{array}{l}5=\text { Já realizada } \\
4=\text { Em implantação } \\
3=\text { Em estudo } \\
2=\text { Prevista } \\
1=\text { Não prevista }\end{array}$ & Ordinal \\
\hline
\end{tabular}




\begin{tabular}{|c|c|c|c|c|}
\hline & $\begin{array}{l}\text { Qualidade da } \\
\text { Infraestrutura Física: } \\
\text { Modais de Transporte } \\
\text { (evolução nos últimos } \\
5 \text { anos) }\end{array}$ & $\begin{array}{l}1 \text { - Modal marítimo } \\
2 \text { - Modal aéreo } \\
3 \text { - Modal rodoviário } \\
4 \text { - Modal ferroviário }\end{array}$ & $\begin{array}{l}5=\text { Melhorou } \\
4=\text { Discreta melhora } \\
3=\text { Manteve-se } \\
2=\text { Discreta piora } \\
1=\text { Piorou }\end{array}$ & Ordinal \\
\hline & $\begin{array}{l}\text { Qualidade da } \\
\text { Infraestrutura Burocrática: } \\
\text { Receita Federal e } \\
\text { Legislação (evolução } \\
\text { nos últimos } 5 \text { anos) }\end{array}$ & $\begin{array}{l}5 \text { - Burocracia na exportação } \\
6 \text { - Burocracia na importação }\end{array}$ & $\begin{array}{l}5=\text { Melhorou } \\
4=\text { Discreta melhora } \\
3=\text { Manteve-se } \\
2=\text { Discreta piora } \\
1=\text { Piorou }\end{array}$ & Ordinal \\
\hline & $\begin{array}{l}\text { Qualidade da } \\
\text { Infraestrutura: Custo } \\
\text { Brasil (em 2003) }\end{array}$ & $\begin{array}{l}7 \text { - Gastos com demurrage de navios } \\
8 \text { - Gastos com demurrage/detention de } \\
\text { contêineres } \\
9 \text { - Gastos com diárias de caminhões } \\
10 \text { - Gastos com diárias de trens } \\
11 \text { - Gastos com transporte premium }\end{array}$ & US\$ & Razão \\
\hline \multirow[t]{4}{*}{$\begin{array}{l}\text { Quinta } \\
\text { Pergunta }\end{array}$} & $\begin{array}{l}\text { Qualidade da } \\
\text { Infraestrutura: EADIs }\end{array}$ & 12 - Utilização de EADIs no presente & $\begin{array}{l}5=\text { Sempre } \\
4=\text { Quase sempre } \\
3=\text { Às vezes } \\
2=\text { Quase nunca } \\
1=\text { Nunca }\end{array}$ & Ordinal \\
\hline & & 13 - Avaliação das EADls & $\begin{array}{l}5=\text { Ótimo } \\
4=\text { Bom } \\
3=\text { Regular } \\
4=\text { Ruim } \\
5=\text { Péssimo }\end{array}$ & \\
\hline & & 14 - Custo das EADIs & $\begin{array}{l}5=\text { Alto } \\
4=\text { Pouco Alto } \\
3=\text { Razoável } \\
2=\text { Pouco Baixo } \\
1=\text { Baixo }\end{array}$ & \\
\hline & & 15 - Utilização de EADIs no futuro & $\begin{array}{l}5=\text { Aumentar } \\
4=\text { Aumentar Pouco } \\
3=\text { Manter } \\
2=\text { Diminuir } \\
1=\text { Diminuir Pouco }\end{array}$ & \\
\hline
\end{tabular}

Finalmente, com relação ao nível máximo de significância considerado aceitável nesta pesquisa, deve ser destacado que foi adotado o valor 0,10. De acordo com Mentzer e Flint (1997), níveis de significância entre 0,05 e 0,10 podem ser aceitos em pesquisas exploratórias em logística.

\section{ANÁLISE DOS RESULTADOS}

Inicialmente foram calculadas estatísticas descritivas para as variáveis apresentadas nas Tabelas 1 e 2 . Os resultados para as médias são apresentados nas Figuras 2, 3 e 4, segmentando-se pelo setor da economia, pelo tipo de carga e pela estrutura do processo produtivo.
Uma rápida inspeção nessas figuras permite verificar a heterogeneidade de percepções sobre os diferentes aspectos relacionados à infraestrutura logística de exportação, sob diferentes setores da economia, tipo de carga e estrutura do processo produtivo. Conforme apontado na metodologia, essa diversidade de resultados favorece uso de técnicas multivariadas de análise de dados, não apenas para confirmar se as diferentes médias possuem algum resultado estatístico significativo, mas também para mensurar as relações propostas nas perguntas da pesquisa.

Com relação à primeira pergunta, a extração dos fatores principais das vinte e seis variáveis relacionadas a possíveis dificuldades logísticas para exportação (cf. Tabela 1) foi conduzida por Análise Fatorial com rotação Varimax Nor- 
malizada, para a amostra com 101 observações. Os resultados são apresentados na Tabela 3, apenas para os fatores de carga acima de 0,50 e eigenvalues maiores que 1 . Segundo Tabachnik e Fidell (2001), apenas os fatores de carga acima de 0,50 ( $25 \%$ de sobreposição na variância) devem ser interpretados, podendo, nestes casos, ser afirmado que a variável representaria uma boa medida do fator. Dessa forma, seis fatores principais representam as diferentes dimensões de dificuldades logísticas à exportação:

- As variáveis Infraestrutura Ferroviária de Escoamento, Infraestrutura Hidroviária de Escoamento, Infraestrutura de Intermodalidade, Financiamentos do Governo, Disponibilidade de Armazenagem nos Portos Nacionais, Acesso aos Portos Brasileiros e Filas nos Portos Brasileiros compõem o Fator 1, interpretado como a Dificuldade de Escoamento e Acesso aos Portos;

- As variáveis Infraestrutura Portuária de Escoamento, Burocracia, Receita Federal-Horário de Funcionamento, Tempo de Liberação de Mercadorias e Greves compõem o Fator 2, interpretado como a Dificuldade de Movimentação de Cargas nos Portos;
- As variáveis Infraestrutura Aeroportuária de Escoamento, Disponibilidade de Rotas Internacionais de Aviões e Frequência de Aviões compõem o Fator 3, interpretado como a Dificuldade de Disponibilidade do Transporte Aéreo;

- As variáveis Disponibilidade de Rotas Internacionais de Navios, Frequência de Navios e Falta de Contêineres compõem o Fator 4, interpretado como a Dificuldade de Disponibilidade do Transporte Marítimo;

- As variáveis Deficiência dos Portos nos Países Importadores e Distribuição nos Países Importadores compõem o Fator 5, interpretado como a Dificuldade de Comercialização Internacional;

- Finalmente, as variáveis Infraestrutura Rodoviária de Escoamento e Custos do Transporte Nacional compõem o Fator 6, interpretado como a Dificuldade de Competitividade em Custos no Transporte Rodoviário.

Os resultados apresentados na Tabela 3 permitem inferir que as dificuldades logísticas estão dispersas por diferen-

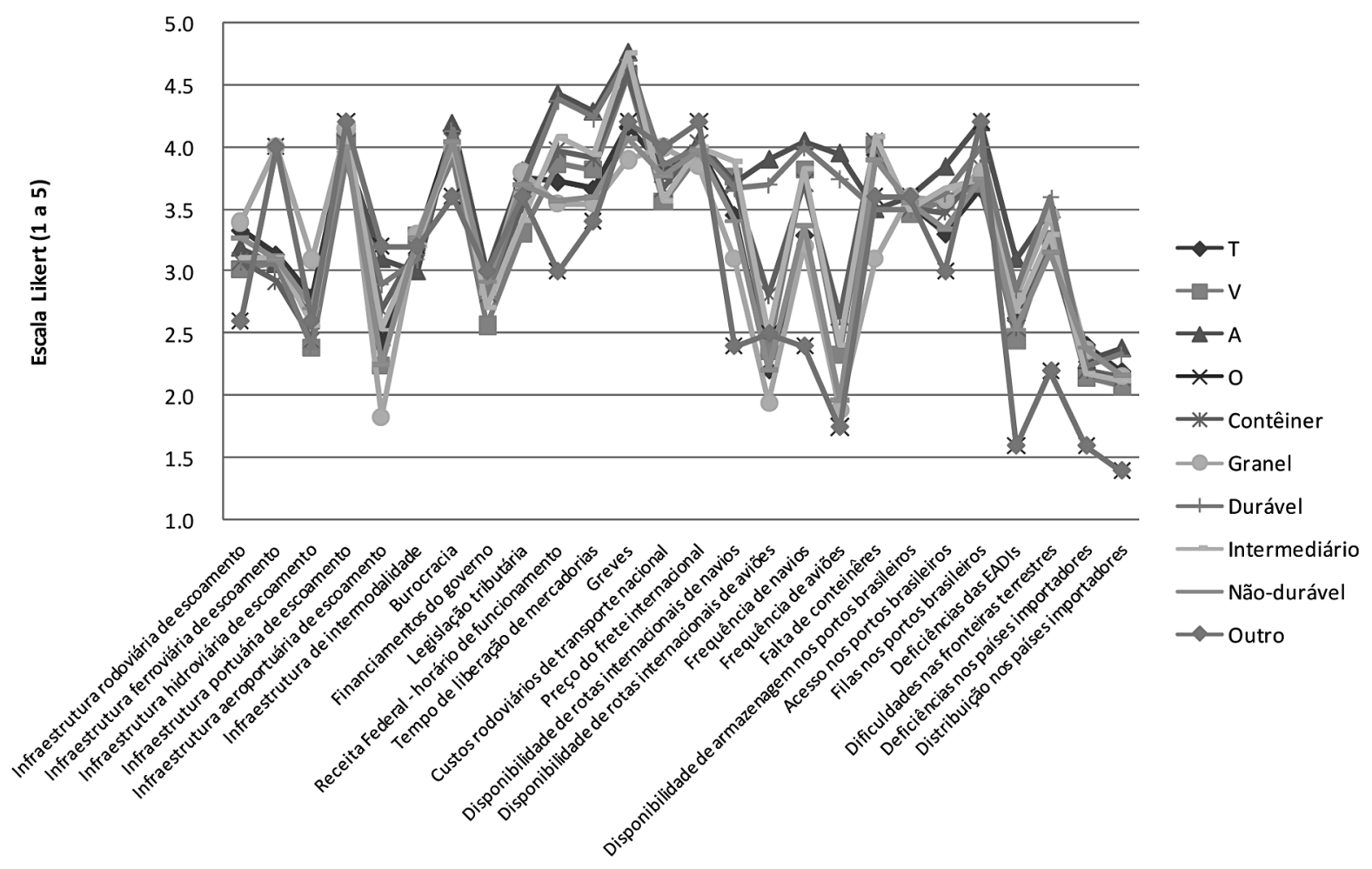

Figura 2: Percepções com relação às dificuldades à exportação (valores médios). 
Wanke, P. F.; Hijjar, M. F. Exportadores Brasileiros: Estudo Exploratório das Percepções sobre a Qualidade da Infraestrutura Logística. Produção, v. 19, n. 1, p. 143-162, 2009

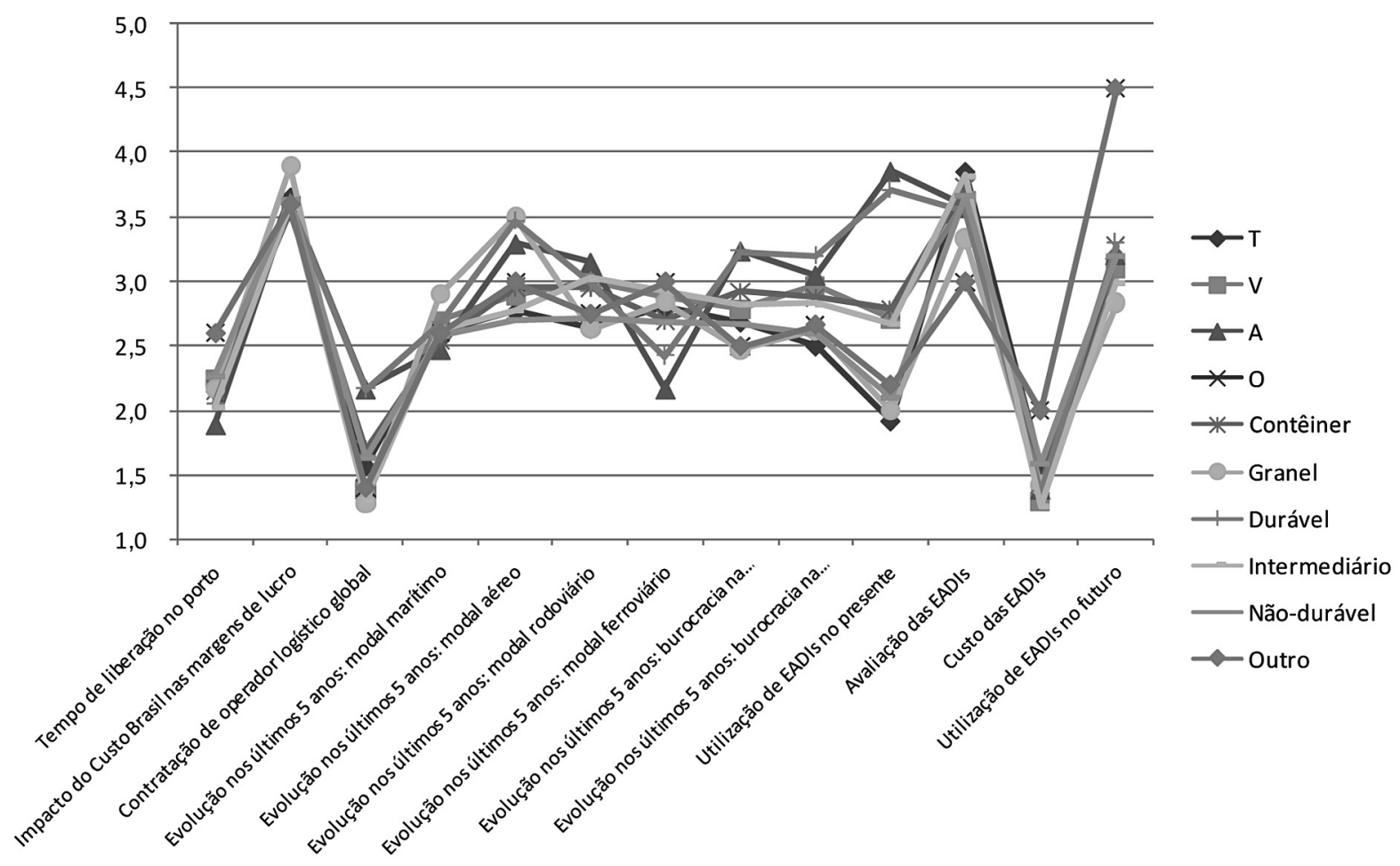

Figura 3: Percepções com relação à qualidade da infraestrutura logística (valores médios).

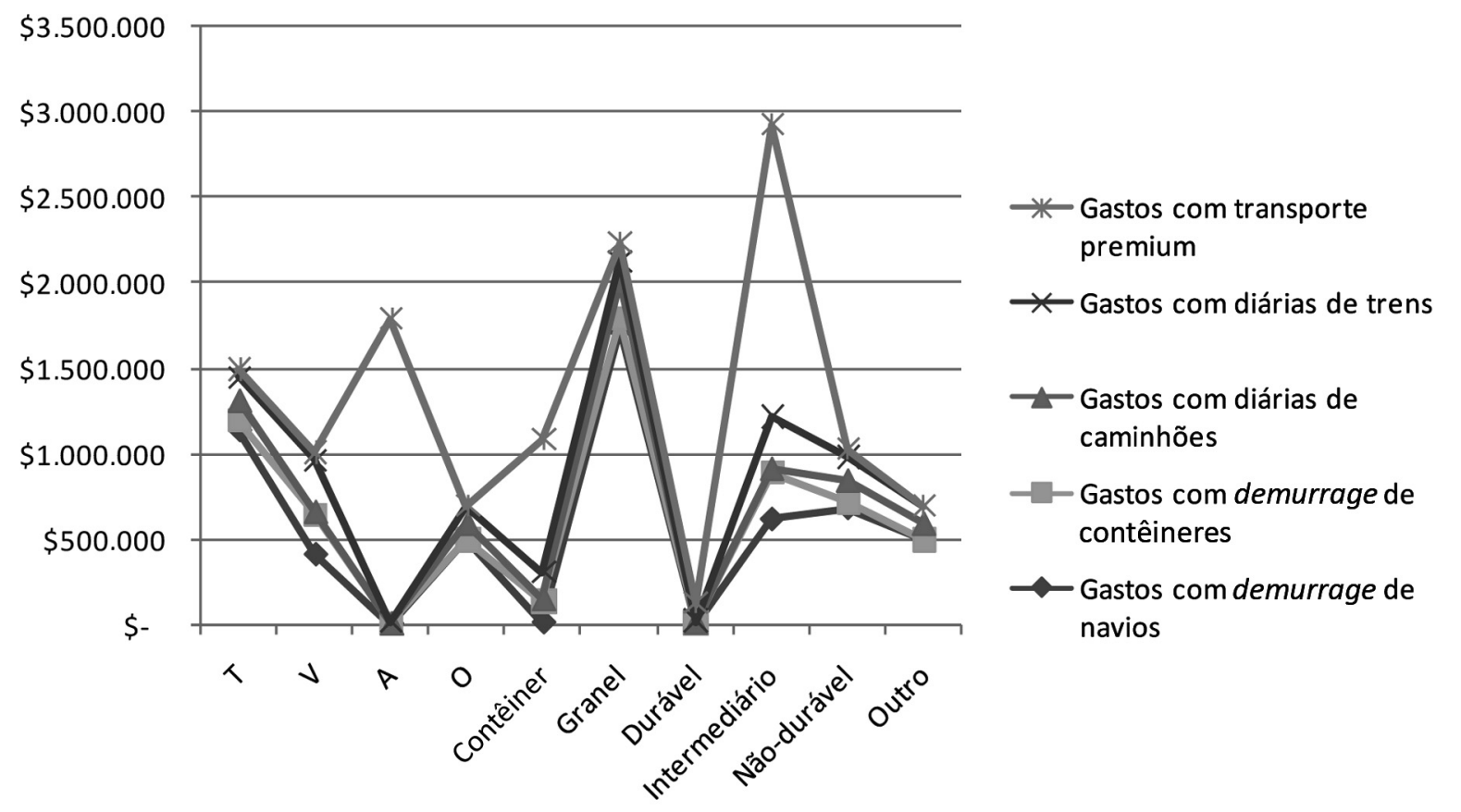

Figura 4: Gastos relacionados à qualidade da infraestrutura logística (valores médios). 
tes elos das cadeias de suprimentos exportadoras. Esses resultados também permitem inferir comparativamente tomando por base o percentual de variância explicada por cada fator - que o acesso e a movimentação nos portos constituem dificuldades logísticas à exportação maiores que a disponibilidade de transporte aéreo - exportação via aeroportos, sobretudo de componentes de maior valor agregado e menor volume - e a competitividade em custos no transporte rodoviário - exportação via rodovias, sobretudo para o Mercosul.

Com relação à segunda pergunta, a validação do tipo de carga (contêiner/granel) como dimensão de segmentação dos exportadores brasileiros foi conduzida através de Análise de Regressão Logística Simples com os seis fatores das dificuldades logísticas como variáveis independentes. O tipo de carga granel foi considerado como a categoria de referência

Tabela 3: Resultados da extração dos principais fatores das dificuldades logísticas à exportação.

\begin{tabular}{|c|c|c|c|c|c|}
\hline Fatores & $\begin{array}{l}\text { \% da variância } \\
\text { explicada }\end{array}$ & Componentes & $\begin{array}{c}\text { Fator da } \\
\text { carga }\end{array}$ & $\begin{array}{l}\text { Coeficiente } \\
\text { do fator }\end{array}$ & Comunalidade \\
\hline \multirow{7}{*}{$\begin{array}{l}1 \text { - Dificuldade } \\
\text { de escoamento e } \\
\text { acesso aos portos }\end{array}$} & \multirow[t]{7}{*}{15,53} & Infraestrutura ferroviária de escoamento & 0,69 & 0,23 & 0,63 \\
\hline & & Infraestrutura hidrovária de escoamento & 0,58 & 0,19 & 0,42 \\
\hline & & Infraestrutura de intermodalidade & 0,64 & 0,20 & 0,50 \\
\hline & & Financiamentos do governo & 0,62 & 0,18 & 0,49 \\
\hline & & Disponibilidade de armazenagem & 0,63 & 0,19 & 0,70 \\
\hline & & Acesso aos portos & 0,64 & 0,14 & 0,76 \\
\hline & & Fila nos portos & 0,72 & 0,22 & 0,78 \\
\hline \multirow{5}{*}{$\begin{array}{l}2 \text { - Dificuldade de } \\
\text { movimentação de } \\
\text { cargas }\end{array}$} & \multirow[t]{5}{*}{14,97} & Infraestrutura portuária de escoamento & 0,59 & 0,11 & 0,70 \\
\hline & & Burocracia & 0.81 & 0,31 & 0,75 \\
\hline & & Receita Federal & 0,80 & 0,26 & 0,73 \\
\hline & & Tempo de Liberação de Mercadorias & 0,81 & 0,25 & 0,77 \\
\hline & & Greves & 0,65 & 0,19 & 0,58 \\
\hline \multirow{3}{*}{$\begin{array}{l}3 \text { - Dificuldade de } \\
\text { disponibilidade do } \\
\text { transporte aéreo }\end{array}$} & \multirow[t]{3}{*}{11,31} & Infraestrutura aeroportuária de escoamento & 0,76 & 0,28 & 0,66 \\
\hline & & Disponibilidade de rotas internacionais de aviões & 0,95 & 0,36 & 0,91 \\
\hline & & Frequência de aviões & 0,92 & 0,35 & 0,88 \\
\hline \multirow{3}{*}{$\begin{array}{l}4 \text { - Dificuldade de } \\
\text { disponibilidade do } \\
\text { transporte marítimo }\end{array}$} & \multirow[t]{3}{*}{9,41} & Disponibilidade de rotas internacionais de navios & 0,74 & 0,31 & 0,82 \\
\hline & & Frequência de navios & 0,79 & 0,35 & 0,76 \\
\hline & & Falta de contêineres & 0,61 & 0,30 & 0,48 \\
\hline \multirow{2}{*}{$\begin{array}{l}5 \text { - Dificuldade de } \\
\text { comercialização } \\
\text { internacional }\end{array}$} & \multirow[t]{2}{*}{7,80} & Deficiência dos portos nos países importadores & 0,84 & 0,44 & 0,81 \\
\hline & & Distribuição nos países importadores & 0,83 & 0,45 & 0,83 \\
\hline \multirow{2}{*}{$\begin{array}{l}6 \text { - Dificuldade de } \\
\text { competitividade em } \\
\text { custos no transporte } \\
\text { rodoviário }\end{array}$} & \multirow[t]{2}{*}{$6,45 \%$} & Infraestrutura rodoviária de escoamento & 0,60 & 0,37 & 0,50 \\
\hline & & Custo de transporte nacional & 0,72 & 0,42 & 0,71 \\
\hline
\end{tabular}

Medidas de avaliação: KMO =0,708; Qui-quadrado=1196,965 (sign <0,000) 
da variável dependente. De acordo com os coeficientes da Tabela 4, os fatores Dificuldade de Escoamento e Acesso aos Portos (Fator 1), Dificuldade de Disponibilidade de Transporte Aéreo (Fator 3) e Dificuldade de Disponibilidade de Transporte Marítimo (Fator 4) discriminam simultaneamente os tipos de cargas exportadas (contêiner ou granel) a um nível de significância inferior a 0,10. De acordo com o R Quadrado de Nagelkerke, os principais fatores das dificuldades logísticas à exportação explicam isoladamente $27,5 \%$ da segmentação dos exportadores pelo tipo de carga.

\section{S resultados podem ser utilizados pelos setores público e privado, respectivamente,} na formulação de políticas públicas específicas paração dos exportadores em dois grupos com base em semelhanças nos diferentes fatores das dificuldades logísticas. Foram considerados os seis fatores apresentados na Tabela 3. De acordo com os resultados apresentados nas Tabelas 5 e 6, os fatores das dificuldades logísticas à exportação que apresentam maior distância absoluta entre os centróides dos dois grupos são a Movimentação de Carga nos Portos (Fator 2), a Disponibilidade de Transporte Marítimo (Fator 4) e a Comercialização Internacional (Fator 5). De acordo com a Tabela 6, não é possível distinguir os dois grupos formados com relação aos fatores 1,3 e 6 .

Deve ser ressaltado que os resultados dos testes F, apresentados na Tabela 6, devem ser empregados apenas para descrever geometricamente os grupos formados, já que estes foram determinados de modo a maximizar as diferenças nos fatores considerados. Os níveis de significância observados, portanto, não podem ser interpretados como testes

Os coeficientes positivos dos Fatores 3 e 4 indicam que os exportadores do tipo de carga contêiner tendem a considerar a Disponibilidade do Transporte Aéreo e a Disponibilidade do Transporte Marítimo fatores mais críticos que os exportadores de cargas a granel. Por sua vez, o coeficiente negativo do Fator 1 indica que os exportadores do tipo de carga granel tendem a considerar o Escoamento e o Acesso aos Portos um fator mais crítico que os exportadores de cargas em contêineres.

Com relação à terceira pergunta, ou seja, a identificação de outras dimensões relevantes para a segmentação dos exportadores foi conduzida Análise de Clusters para a se- da hipótese de igualdade de médias.

Os resultados apresentados na Tabela 5 permitem inferir que os exportadores podem apresentar duas percepções distintas com relação a criticidade da operação porto-a-porto (movimentação portuária, disponibilidade de transporte marítimo e comercialização internacional) nas cadeias de suprimento exportadoras. No primeiro grupo, os exportadores consideram crítica a operação porto-a-porto, distinguindo-a claramente dos demais modais de transporte: ferroviário, aéreo e rodoviário. No segundo grupo, os exportadores não consideram a operação porto-a-porto como problema crítico em suas cadeias.

Tabela 4: Análise de regressão logística simples para o tipo de carga em função dos fatores das dificuldades logísticas à exportação.

\begin{tabular}{cccccc}
\hline & Coeficientes & Erro Padrão & Wald & Graus de Liberdade & Significância \\
\hline Fator 1 & $-0,61$ & 0,37 & 2,77 & 1,00 & $\mathbf{0 , 1 0}$ \\
Fator 2 & 0,46 & 0,31 & 2,16 & 1,00 & 0,14 \\
Fator 3 & 0,71 & 0,36 & 3,95 & 1,00 & $\mathbf{0 , 0 5}$ \\
Fator 4 & 0,68 & 0,34 & 3,84 & 1,00 & $\mathbf{0 , 0 5}$ \\
Fator 5 & $-0,12$ & 0,30 & 0,17 & 1,00 & 0,68 \\
Fator 6 & $-0,27$ & 0,31 & 0,77 & 1,00 & 0,38 \\
Constante & 1,66 & 0,36 & 21,25 & 1,00 & 0,00 \\
\hline
\end{tabular}

Categoria de referência: tipo de carga granel

Cox \& Snell R Quadrado $=17,8 \%$

Nagelkerke R Quadrado $=27,5 \%$

Qui-quadrado para o modelo $=15,463(\mathrm{Sig}=0,017)$ 
Com relação à quarta pergunta, a caracterização da nova dimensão de segmentação identificada nas Tabelas 5 e 6, ou seja, a criticidade da operação porto-a-porto, foi conduzida por Análise de Correlação Não-Paramétrica, em virtude das diferentes escalas adotadas para medir diferentes características dos exportadores. Os resultados são apresentados na Tabela 7. Todas as variáveis apresentaram significância inferior a 0,05 .

O coeficiente positivo da variável Tempo de Liberação no Porto e os coeficientes negativos das demais variáveis indicam que os exportadores que consideram crítica a operação porto-a-porto avaliam como muito lento o tempo decorrido desde a chegada no porto até o efetivo embarque; consideram sua capacidade de produção um entrave à exportação; estimam como elevado o percentual de perda de produtos causado por ineficiências na manipulação, transporte e armazenagem; consideram que o Custo Brasil muito afeta suas margens de lucro e já contrataram operador logístico global para gerenciamento das exportações (cf. Tabela 7).
Ainda com relação à quarta pergunta, a caracterização da nova dimensão de segmentação identificada nas Tabelas $5 \mathrm{e}$ 6 também foi conduzida por Análise de Regressão Logística Simples, com o Setor da Economia (Durável, Não-Durável e Insumos Industriais/Produtos Intermediários) e o Tipo de Processo Produtivo (V, A e T) como variáveis independentes. A criticidade da operação porto-a-porto foi considerada como a categoria de referência da variável dependente. De acordo com os coeficientes da Tabela 8, apenas o Setor de Insumos Industriais/Produtos Intermediários discrimina a criticidade da operação porto-a-porto a um nível de significância inferior a 0,10.

O coeficiente negativo do Setor de Insumos Industriais/ Produtos Intermediários indica que os exportadores que consideram crítica a operação porto-a-porto na exportação tendem a pertencer às indústrias Química e Petroquímica, de Papel e Celulose, de Siderurgia e Mineração e Metalomecânica. Tomando por base os resultados da Tabela 7 , é possível inferir, por exemplo, que exportadores dessas indústrias apresentam limitações na capacidade produtiva,

Tabela 5: Centróides dos grupos de exportadores (clusters).

\begin{tabular}{ccc}
\hline & \multicolumn{2}{c}{ Grupo ou Cluster } \\
\hline & 1 & 2 \\
\cline { 2 - 3 } Fator 1 & 0,11 & $-0,30$ \\
Fator 2 & 0,44 & $-1,21$ \\
Fator 3 & $-0,04$ & 0,11 \\
Fator 4 & 0,18 & $-0,51$ \\
Fator 5 & 0,14 & $-0,39$ \\
Fator 6 & $-0,03$ & 0,08 \\
\hline
\end{tabular}

Tabela 6: Análise de variância dos grupos.

\begin{tabular}{|c|c|c|c|c|c|c|}
\hline & \multicolumn{2}{|c|}{ Grupo ou Cluster } & \multicolumn{2}{|c|}{ Erro } & \multirow[t]{2}{*}{$\mathbf{F}$} & \multirow[t]{2}{*}{ Significância } \\
\hline & $\begin{array}{l}\text { Quadrado } \\
\text { médio }\end{array}$ & $\begin{array}{c}\text { Graus de } \\
\text { Liberdade }\end{array}$ & $\begin{array}{c}\text { Quadrado } \\
\text { médio }\end{array}$ & $\begin{array}{c}\text { Graus de } \\
\text { Liberdade }\end{array}$ & & \\
\hline Fator 1 & 2,49 & 1,00 & 0,98 & 77,00 & 2,54 & 0,12 \\
\hline Fator 2 & 41,58 & 1,00 & 0,47 & 77,00 & 87,92 & $\mathbf{0 , 0 0}$ \\
\hline Fator 3 & 0,35 & 1,00 & 1,01 & 77,00 & 0,35 & 0,56 \\
\hline Fator 4 & 7,30 & 1,00 & 0,92 & 77,00 & 7,95 & 0,01 \\
\hline Fator 5 & 4,39 & 1,00 & 0,96 & 77,00 & 4,59 & 0,04 \\
\hline Fator 6 & 0,18 & 1,00 & 1,01 & 77,00 & 0,18 & 0,67 \\
\hline
\end{tabular}


são duramente afetados por ineficiências no manuseio e no transporte (perda de produtos e margens de lucro) e contratam operadores logísticos globais.

Com relação à quinta pergunta, a relação das variáveis das diferentes dimensões de percepção da qualidade da infraestrutura com os principais critérios de segmentação dos exportadores (tipo de carga e criticidade da operação porto-a-porto) foi conduzida por diferentes métodos, em virtude da diferente natureza das escalas adotadas (cf. Tabela 2).

Especificamente com relação às variáveis da dimensão Qualidade da Infraestrutura Física - Modais de Transporte, foi conduzida Análise de Regressão Ordinal com o nível Melhorou da variável dependente como a categoria de referência. A variável criticidade da operação porto-a-porto discrimina significativamente, da categoria de referência, os demais níveis apenas para o Modal Marítimo $(\mathrm{p}<0,001)$. Seu coeficiente negativo indica que os exportadores que consideram crítica a operação porto-a-porto nas suas operações têm maiores chances de perceber piora na infraestrutura do
Modal Marítimo nos últimos cinco anos. Essa percepção não é influenciada pelo tipo de carga para nenhum dos modais de transporte analisados (cf. Tabela 9).

Já com relação às variáveis da dimensão Qualidade da Infraestrutura Burocrática - Receita Federal e Legislação, foi conduzida Análise de Regressão Ordinal com o nível Melhorou da variável dependente como a categoria de referência. As variáveis tipo de carga e criticidade da operação porto-a-porto discriminam significativamente, da categoria de referência, os demais níveis apenas para a Burocracia na Exportação $(p<0,05)$. Seus coeficientes negativos indicam que os exportadores de carga granel que consideram crítica a operação porto-a-porto têm maiores chances de perceber piora na Burocracia na Exportação nos últimos cinco anos. A variável criticidade da operação porto-a-porto discrimina significativamente, da categoria de referência, os demais níveis apenas para a Burocracia na Importação $(\mathrm{p}<0,10)$. Seu coeficiente negativo indica que apenas os importadores que consideram crítica a operação porto-a-porto têm maiores chances de perceber piora na

Tabela 7: Análise de correlação não paramétrica.

\begin{tabular}{lccc}
\hline \multicolumn{1}{c}{ Variáveis } & Coeficientes & Significância & N \\
\hline Limitação da Capacidade Produtiva da Empresa & $-0,22$ & $\mathbf{0 , 0 3}$ & 79 \\
Percentual Estimado de Perda de Produtos & $-0,41$ & $\mathbf{0 , 0 2}$ & 72 \\
Tempo de Liberação no Porto & 0,29 & $\mathbf{0 , 0 1}$ & 75 \\
Impacto do Custo Brasil nas Margens de Lucro & $-0,26$ & $\mathbf{0 , 0 1}$ & 77 \\
Contratação de Operador Logístico Global & $-0,34$ & $\mathbf{0 , 0 0}$ & 70 \\
\hline
\end{tabular}

Tabela 8: Análise de regressão logística simples para a criticidade da operação porto-a-porto em função do setor da economia e da estrutura do processo produtivo.

\begin{tabular}{lccccc}
\hline & Coeficientes & Erro Padrão & Wald & Graus de Liberdade & Significância \\
\hline Insumos Industriais & $-2,93$ & 1,78 & 2,73 & 1,00 & $\mathbf{0}, \mathbf{1 0}$ \\
Bens Duráveis & $-1,25$ & 1,20 & 1,09 & 1,00 & 0,30 \\
Bens Não Duráveis & $-1,94$ & 1,90 & 1,04 & 1,00 & 0,31 \\
Tipo T & 1,13 & 1,65 & 0,47 & 1,00 & 0,49 \\
Tipo V & 1,45 & 1,42 & 1,05 & 1,00 & 0,31 \\
Constante & $-0,00$ & 1,00 & 0,00 & 1,00 & 1,00 \\
\hline
\end{tabular}

Categoria de referência: criticidade da operação porto-a-porto

Cox \& Snell R Quadrado $=5,2 \%$

Nagelkerke R Quadrado $=8,0 \%$

Qui-quadrado para o modelo $=4,17(\mathrm{Sig}=0,52)$ 
Burocracia na Importação nos últimos cinco anos (cf. Tabela 10).

Por sua vez, com relação às variáveis da dimensão Qualidade da Infraestrutura - Custo Brasil, foi conduzida Análise de Regressão Múltipla com o tipo de carga e a criticidade da operação porto-a-porto como variáveis explicativas. A variável tipo de carga explica significativamente os gastos com Demurrage de Navios e Diárias de Caminhões ( $\mathrm{p}<$ 0,01 ). Seu coeficiente negativo indica que os exportadores de cargas a granel gastaram a mais, em média, US\$1,709 milhão em demurrage de navios e US\$ 286 mil em diárias de caminhões, no ano de 2003, que os exportadores de cargas em contêineres (cf. Tabela 11).

Finalmente, com relação às variáveis da dimensão Qualidade da Infraestrutura - EADIs, foi conduzida Análise de Regressão Ordinal com o maior nível da variável dependente como a categoria de referência. A variável criticidade da operação porto-a-porto discrimina significativamente, da categoria de referência, os demais níveis apenas para a Utilização de EADIs no Futuro $(\mathrm{p}<0,05)$. Seu coeficiente positivo indica que os exportadores que consideram crítica a operação porto-a-porto têm maiores chances de utilizar os serviços de EADIs no futuro, contrariamente aos exportadores que não consideram crítica a operação porto-a-porto. Já a variável tipo de carga discrimina significativamente, da categoria de referência, os demais níveis apenas para a Utilização de EADIs $(\mathrm{p}<0,10)$. Seu coeficiente negativo indica que atualmente os exportadores de carga a granel tendem a utilizar menos os serviços de EADIs que os exportadores de cargas em contêineres (cf. Tabela 12).

\section{DISCUSSÃO DOS RESULTADOS}

Os resultados da pesquisa representam avanços teóricos no entendimento das principais dificuldades logísticas à exportação e das diferentes percepções sobre qualidade dessa infraestrutura no Brasil. Ao contrário do que indica o senso comum, esses elementos não são homogêneos a todos os exportadores e são influenciados significativamente pelo tipo de carga exportada (contêiner ou granel) e pela criticidade da operação porto-a-porto. Deve ser ressaltado, no entanto, que algumas percepções comuns sobre a questão

Tabela 9: Análises de regressão ordinal para as variáveis pesquisadas na dimensão qualidade da infraestrutura física - modais de transporte.

\begin{tabular}{|c|c|c|c|c|c|c|c|}
\hline \multirow[b]{2}{*}{ V. pesquisada } & & \multirow[b]{2}{*}{ Coeficiente } & \multirow[b]{2}{*}{ Wald } & \multirow[b]{2}{*}{ Significância } & \multicolumn{3}{|c|}{ Avaliação global do modelo } \\
\hline & & & & & $\mathbf{N} \mathbf{R}$ & Qui-quadrado & Significância \\
\hline \multirow{3}{*}{$\begin{array}{l}\text { Modal } \\
\text { marítimo }\end{array}$} & Tipo de carga: granel & 0,32 & 0,39 & 1,00 & $15,0 \%$ & 12,01 & 0,00 \\
\hline & Operação & $-1,61$ & 9,55 & 0,00 & & & \\
\hline & Porto-a-porto: crítica & & & & & & \\
\hline \multirow{3}{*}{$\begin{array}{l}\text { Modal } \\
\text { aéreo }\end{array}$} & Tipo de carga: granel & 0,43 & 0,11 & 0,74 & $4,0 \%$ & 1,74 & 0,42 \\
\hline & Operação & $-0,81$ & 1,37 & 0,24 & & & \\
\hline & Porto-a-porto: crítica & & & & & & \\
\hline \multirow{3}{*}{$\begin{array}{l}\text { Modal } \\
\text { rodoviário }\end{array}$} & Tipo de carga: granel & $-0,46$ & 0,77 & 0,38 & $3,0 \%$ & 1,91 & 0,39 \\
\hline & Operação & $-0,62$ & 1,57 & 0,21 & & & \\
\hline & Porto-a-porto: crítica & & & & & & \\
\hline \multirow{3}{*}{$\begin{array}{l}\text { Modal } \\
\text { ferroviário }\end{array}$} & Tipo de carga: granel & 0,21 & 0,09 & 0,76 & $8,0 \%$ & 2,64 & 0,27 \\
\hline & Operação & $-1,06$ & 1,88 & 0,17 & & & \\
\hline & Porto-a-porto: crítica & & & & & & \\
\hline
\end{tabular}

Categorias de referência - variáveis explicativas: tipo de carga contêiner e operação porto-a-porto não crítica.

Categoria de referência - variável dependente: Melhorou.

Os coeficientes lineares das categorias foram omitidos.

$\mathrm{NR}=$ Nagelkerke $\mathrm{R}^{2}$ 
Wanke, P. F.; Hijjar, M. F. Exportadores Brasileiros: Estudo Exploratório das Percepções sobre a Qualidade da Infraestrutura Logística. Produção, v. 19, n. 1, p. 143-162, 2009

Tabela 10: Análises de regressão ordinal para as variáveis pesquisadas na dimensão qualidade da infraestrutura burocrática - receita federal e legislação.

\begin{tabular}{|c|c|c|c|c|c|c|c|}
\hline \multirow[b]{2}{*}{ V. pesquisada } & & \multirow[b]{2}{*}{ Coeficiente } & \multirow[b]{2}{*}{ Wald } & \multirow[b]{2}{*}{ Significância } & \multicolumn{3}{|c|}{ Avaliação global do modelo } \\
\hline & & & & & N R & Qui-quadrado & Significância \\
\hline \multirow{2}{*}{$\begin{array}{l}\text { Burocracia } \\
\text { na } \\
\text { Exportação }\end{array}$} & Tipo de carga: granel & $-1,03$ & 3,73 & 0,05 & $16,0 \%$ & 12,75 & - \\
\hline & $\begin{array}{l}\text { Operação } \\
\text { Porto-a-porto: crítica }\end{array}$ & $-1,72$ & 10,18 & $\mathbf{0 , 0 0}$ & & & \\
\hline \multirow{2}{*}{$\begin{array}{l}\text { Burocracia } \\
\text { na } \\
\text { Importação }\end{array}$} & Tipo de carga: granel & $-0,62$ & 1,25 & 0,26 & $6,0 \%$ & 3,90 & 0,14 \\
\hline & $\begin{array}{l}\text { Operação } \\
\text { Porto-a-porto: crítica }\end{array}$ & $-0,90$ & 3,02 & 0,08 & & & \\
\hline
\end{tabular}

Categorias de referência - variáveis explicativas: tipo de carga contêiner e operação porto-a-porto não crítica.

Categoria de referência - variável dependente: Melhorou.

Os coeficientes lineares das categorias foram omitidos.

$\mathrm{NR}=$ Nagelkerke $\mathrm{R}^{2}$

Tabela 11: Análises de regressão múltipla para as variáveis pesquisadas na dimensão qualidade da infraestrutura - custo Brasil.

\begin{tabular}{|c|c|c|c|c|c|c|c|}
\hline \multirow[b]{2}{*}{ V. pesquisada } & & \multirow[b]{2}{*}{ Coeficientes } & \multirow[b]{2}{*}{$\mathbf{t}$} & \multirow[b]{2}{*}{ Significância } & \multicolumn{3}{|c|}{ Avaliação global do modelo } \\
\hline & & & & & $\begin{array}{l}\text { R Quadrado } \\
\text { ajustado }\end{array}$ & $\mathbf{F}$ & Significância \\
\hline \multirow{3}{*}{$\begin{array}{l}\text { Demurrage } \\
\text { de Navios }\end{array}$} & Constante & $3.421 .731,75$ & 3,36 & 0,00 & $40,0 \%$ & 7,57 & 0,00 \\
\hline & Tipo de carga: granel & $-1.709 .885,71$ & $-3,89$ & 0,00 & & & \\
\hline & $\begin{array}{l}\text { Operação Porto-a- } \\
\text { porto }\end{array}$ & $14.822,22$ & 0,03 & 0,98 & & & \\
\hline \multirow{3}{*}{$\begin{array}{l}\text { Demurrage/ } \\
\text { Detention de } \\
\text { Contêineres }\end{array}$} & Constante & $104.000,00$ & 0,15 & 0,88 & - & 0,15 & 0,86 \\
\hline & Tipo de carga: granel & $97.956,25$ & 0,29 & 0,78 & & & \\
\hline & $\begin{array}{l}\text { Operação Porto-a- } \\
\text { porto }\end{array}$ & $-141.956,25$ & $-0,50$ & 0,62 & & & \\
\hline \multirow{3}{*}{$\begin{array}{l}\text { Diárias de } \\
\text { Caminhões }\end{array}$} & Constante & $611.048,02$ & 2,66 & 0,02 & $30,0 \%$ & 4,17 & 0,04 \\
\hline & Tipo de carga: granel & $-285.567,84$ & $-2,89$ & 0,01 & & & \\
\hline & $\begin{array}{l}\text { Operação Porto-a- } \\
\text { porto }\end{array}$ & $-16.384,14$ & $-0,15$ & 0,88 & & & \\
\hline \multirow{3}{*}{$\begin{array}{l}\text { Diárias de } \\
\text { Trens }\end{array}$} & Constante & $398.500,00$ & 0,91 & 0,46 & - & 0,23 & 0,81 \\
\hline & Tipo de Carga & $-48.500,00$ & $-0,27$ & 0,81 & & & \\
\hline & $\begin{array}{l}\text { Operação Porto-a- } \\
\text { porto }\end{array}$ & $-150.000,00$ & $-0,68$ & 0,56 & & & \\
\hline \multirow{3}{*}{$\begin{array}{l}\text { Transporte } \\
\text { Premium }\end{array}$} & Constante & $189.000,00$ & 0,04 & 0,97 & - & 0,31 & 0,75 \\
\hline & Tipo de Carga & $1.226 .250,00$ & 0,52 & 0,63 & & & \\
\hline & $\begin{array}{l}\text { Operação Porto-a- } \\
\text { porto }\end{array}$ & $-1.315 .250,00$ & $-0,71$ & 0,51 & & & \\
\hline
\end{tabular}


exportadora são corroboradas nesse estudo: as dificuldades logísticas estão de fato presentes em todas as etapas da cadeia exportadora e elas tendem a ser maiores em portos do que em aeroportos e rodovias (cf. Tabela 3 ).

Do ponto de vista prático, os resultados relativos à segmentação dos exportadores podem ser utilizados pelos setores público e privado, respectivamente, na formulação de políticas públicas específicas por segmento e na tomada de decisões gerenciais com vistas à maior eficiência operacional.

Por exemplo, com relação ao tipo de carga (contêiner ou granel) tornam-se evidentes as prioridades competitivas do exportador. Exportadores de cargas em contêineres consideram como principais dificuldades à exportação a disponibilidade de transporte marítimo e a disponibilidade de transporte aéreo. Sua principal preocupação é com a frequência de navios e aviões, que em última instância vão se refletir no tempo de resposta da operação porto-a-porto ou aeroporto-a-aeroporto. Provavelmente uma maior utilização de EADIs por esse segmento exportador deve amortecer o impacto da dificuldade de escoamento e acesso aos portos/aeroportos dos carregamentos contêinerizados. As EADIs estão se firmando como um importante meio para tornar mais ágil o escoamento e o acesso de cargas nos portos e aeroportos, ao passo que constituem um paliativo aos gargalos decorrentes dos reduzidos investimentos nessa etapa da cadeia.

Por outro lado, exportadores de cargas a granel (basicamente minérios e grãos) consideram como principal dificuldade logística à exportação o escoamento e acesso aos portos. Não obstante os reduzidos investimentos em infraestrutura física nos últimos anos, esses exportadores também percebem uma sensível piora na burocracia para a exportação. Isso talvez seja reflexo da carência de mecanismos similares às EADIs, que "compensem" as longas filas e tempos de espera no escoamento e acesso de cargas aos portos, decorrentes de deficiências na infraestrutura física. Um reflexo claro desses longos tempos de espera no acesso aos portos é a incapacidade de coordenar o transbordo dos carregamentos dos caminhões diretamente para os navios, implicando em substanciais gastos médios por exportador em demurrage de navios e diárias de caminhões. Em 2003, exportadores de cargas a granel gastaram US\$1,710 milhão a mais que exportadores de cargas contêinerizadas em demurrage de navios e US $\$ 286$ mil a mais em diárias de caminhões. Considerando que cargas a granel são fundamentalmente

Tabela 12: Análises de regressão ordinal para as variáveis pesquisadas na dimensão da infraestrutura - EADls.

\begin{tabular}{|c|c|c|c|c|c|c|c|}
\hline \multirow[b]{2}{*}{ V. pesquisada } & & \multirow[b]{2}{*}{ Coeficiente } & \multirow[b]{2}{*}{ Wald } & \multirow[b]{2}{*}{ Significância } & \multicolumn{3}{|c|}{ Avaliação global do modelo } \\
\hline & & & & & N R & Qui-quadrado & Significância \\
\hline \multirow{2}{*}{$\begin{array}{l}\text { Utilização de } \\
\text { EADIs }\end{array}$} & Tipo de carga: granel & $-0,86$ & 2,74 & $\mathbf{0 , 1 0}$ & $5,0 \%$ & 3,70 & 0,16 \\
\hline & $\begin{array}{l}\text { Operação } \\
\text { Porto-a-porto: crítica }\end{array}$ & 0,21 & 0,19 & 0,66 & & & \\
\hline \multirow{2}{*}{$\begin{array}{l}\text { Avaliação } \\
\text { das EADIs }\end{array}$} & Tipo de carga: granel & $-0,52$ & 0,68 & 0,41 & $4,0 \%$ & 2,03 & 0,36 \\
\hline & $\begin{array}{l}\text { Operação } \\
\text { Porto-a-porto: crítica }\end{array}$ & $-0,71$ & 1,49 & 0,22 & & & \\
\hline \multirow{2}{*}{$\begin{array}{l}\text { Custo das } \\
\text { EADIs }\end{array}$} & Tipo de carga: granel & $-1,08$ & 2,50 & 0,11 & $6,0 \%$ & 2,84 & 0,24 \\
\hline & $\begin{array}{l}\text { Operação } \\
\text { Porto-a-porto: crítica }\end{array}$ & $-0,10$ & 0,03 & 0,86 & & & \\
\hline \multirow{2}{*}{$\begin{array}{l}\text { Utilização } \\
\text { de EADls no } \\
\text { Futuro }\end{array}$} & Tipo de carga: granel & $-0,95$ & 1,86 & 0,17 & $13,0 \%$ & 7,19 & 0,03 \\
\hline & $\begin{array}{l}\text { Operação } \\
\text { Porto-a-porto: crítica }\end{array}$ & 1,36 & 4,08 & 0,04 & & & \\
\hline
\end{tabular}

Categorias de referência - variáveis explicativas: tipo de carga contêiner e operação porto-a-porto não crítica.

Categoria de referência - variável dependente: maior nível.

Os coeficientes lineares das categorias foram omitidos.

$\mathrm{NR}=$ Nagelkerke $\mathrm{R}^{2}$ 
commodities e de baixo valor agregado, estes gastos a mais, decorrentes de deficiências na infraestrutura, implicam perda de competitividade internacional relativamente maior no caso dos graneis do que nas cargas contêinerizadas.

Com relação à criticidade da operação porto-a-porto, percebe-se que pode haver situações mais complexas em que (1) parte do problema também está em portos estrangeiros e (2) condições específicas de determinados setores da economia têm levado à piora na percepção da infraestrutura e à terceirização da logística. Indústrias do setor de insumos industriais/produtos intermediários, como Química e

\section{Exportadores de carga a granel tendem a — considerar o acesso aos portos mais crítico que os exportadores de cargas contêinerizadas}

Petroquímica, Papel e Celulose, Siderurgia e Mineração e Metalomecânica tendem a apresentar limitações na capacidade de produção e a ser fortemente afetadas nas margens de lucro por ineficiências no manuseio e no transporte, refletidas sobretudo no percentual de perda de produtos e nos longos tempos para liberação nos portos. Esse quadro provavelmente contribuiu para a percepção da piora da qualidade da infraestrutura física do modal marítimo e da infraestrutura burocrática de importação e exportação nos últimos cinco anos. Como resposta às deficiências estruturais no transporte marítimo, exportadores dessas indústrias estão cada vez mais contratando operadores logísticos internacionais e pretendendo utilizar as EADIs com maior intensidade no futuro.

Provavelmente, a percepção de piora por parte de exportadores dessas indústrias é decorrente das limitações na capacidade de produção, o que geralmente inflige limitações à flexibilidade de resposta operacional, sobretudo no que diz respeito aos tempos de entrega. Dessa forma, e pelo fato dessas indústrias serem intensivas em capital e demandarem vultosos investimentos para expansão da capacidade produtiva, a solução de curto prazo para assegurar níveis mínimos de flexibilidade de resposta operacional passa pela terceirização da logística e não pela produção. De qualquer forma, é impossível afirmar até quando ações como terceirização e utilização de EADIs serão capazes de produzir um efeito compensatório nas deficiências da infraestrutura brasileira.

\section{CONCLUSÕES}

Nesta pesquisa procurou-se avaliar as percepções dos exportadores brasileiros sobre a qualidade da infraestrutura logística à luz de diferentes dimensões de segmentação. Seus resultados revelaram que, contrariamente ao senso comum, as percepções sobre a infraestrutura física e burocrática, o Custo Brasil e a utilização de EADIs dependem do segmento exportador em questão. Duas dimensões prioritárias para segmentação foram validadas estatisticamente através de análise multivariada: o tipo de carga (granel ou contêiner) e a criticidade da operação porto-a-porto.

Exportadores de carga a granel tendem a considerar o escoamento e o acesso aos portos uma dificuldade logística mais crítica que os exportadores de cargas em contêineres. A dificuldade de coordenar o transbordo das cargas nos caminhões para os navios faz com que os exportadores do primeiro grupo gastem substancialmente mais com demurrage de navios e diárias de caminhões e percebam substancial piora na infraestrutura burocrática de exportação nos últimos cinco anos, comparativamente ao segundo grupo. Já com relação a criticidade da operação porto-a-porto, os exportadores do setor de insumos industriais/ produtos intermediários percebem a piora da qualidade da infraestrutura física do modal marítimo e da burocracia para exportação e importação como reflexo de limitações na capacidade de produção. Para este segmento, contratar operadores logísticos internacionais é economicamente mais vantajoso no curto prazo que expandir a capacidade de produção.

Análises futuras devem ser conduzidas na amostra coletada para complementar o quadro conceitual apresentado. Por exemplo, estas análises teriam como objetivo avaliar as interações entre as duas dimensões-chave para segmentação identificadas nesta pesquisa: tipo de carga e criticidade da operação porto-a-porto. As interações possibilitariam a construção de uma matriz $2 \times 2$, considerando-se simultaneamente o efeito conjunto dessas duas variáveis nas percepções sobre a qualidade da infraestrutura logística. Sua necessidade decorre do fato de parte dos setores de Mineração, Químico e Petroquímico exportarem cargas a granel. Uma limitação do estudo decorre da Análise de Correlação Não Paramétrica, para caracterização dos exportadores que consideram crítica a operação porto-a-porto, com base em variáveis que refletem sua percepção sobre a eficiência operacional na exportação. As análises univariadas são reconhecidamente mais limitadas em sua capacidade explicativa que as análises multivariadas. 


\section{Artigo recebido em 12/2007 Aprovado para publicação em 12/2008}

\section{REFERÊNCIAS}

AGÊNCIA BRASIL. Caminhões no porto de Paranaguá formam filas de 85 quilômetros. Disponível em: <www.ceol.com.br>. Acesso em: 16 abril 2004.

BOUGHEAS, S.; DEMETRIADES, P. O.; MORGENROTH, E.L.W. Infrastructure, transport costs, and trade. Journal of International Economics, v. 47, n. 1, p. 169-189, 1999.

CASTRO, C. M. A prática da pesquisa. São Paulo: Mc-Graw-Hill, 1978.

CHASE, R.B.; AQUILANO, N. J. Production and operations management: a life cycle approach. Homewood: Irwin, 1992.

CLARK, X.; DOLLAR, D.; MICCO, A. Port efficiency, maritime transport costs, and bilateral trade. Journal of Development Economics, v. 75, n. 2, p. 417-450, 2004.

CHIN, A.; TONGZON, J. Maintaining Singapore as a major shipping and air transport hub. In: Toh, T. (Ed.), Competitiveness of the Singapore Economy. Singapore: Singapore University Press, p. 83-114, 1998.

CULLINANE, K.; SONG, D.; WANG, T. The application of mathematical programming approaches to estimating container port production efficiency. Journal of Productivity Analysis, v. 24, p. 73-92, 2005.

DUNN, S. C., SEAKER, R. F., WALLER, M. A. Latent variables in business logistics research: scale development and validation. Journal of Business Logistics, v. 15, n. 2, p. 145-172, 1994.

FLEURY, P. F.; HIJJAR, M. F. Logistics Overview in Brazil 2008. Disponível em: <www.ilos.com.br/ index2.php?option $=$ com_docman\&task $=$ doc view\&gid $=31 \&$ ltemid $=44>$. Acesso em: 6 out. 2008.
FIELD, A. Discovering statistics using SPSS. London: Sage Publications, 2005.

FIGUEIREDO, K. F.; FLEURY, P. F; WANKE, P. Logística e gerenciamento da cadeia de suprimentos: planejamento do fluxo de produtos e dos recursos. São Paulo: Editora Atlas, 2003.

GARVER, M. S., MENTZER, J. T. Logistics research methods: employing structural equation modeling to test for construct validity. Journal of Business Logistics, v. 20, n.1, p. 33-57, 1999.

GUIA DE LOGÍsTICA. EADI - Estação Aduaneira Interior. Disponível em: <www.guiadelogistica. com.br>. Acesso em: 1으. 2004.

HAIR, J. F.; ANDERSON, R. E.; TATHAM, R. L. Multivariate data analysis. New York: Prentice Hall, 1998.

KLEINBAUM, D.; KUPPER, L.; MULLER, K. Applied regression analysis and other multivariable methods. New York: Duxbury Press, 1998.

LIMAO, N.; VENABLES, A. J. Infrastructure, geographical disadvantage, transport costs and trade. The World Bank Economic Review, v. 15, n. 3, p. 451-479, 2001.

MALHOTRA, N. K. Pesquisa de marketing: uma orientação aplicada. Porto Alegre: Bookman, 2001.

MARTÍNEZ-ZARZOSO, I.; SUÁREZ-BURGUET, C.; MENÉNDEZ, L. G. The impact of transport costs on international trade. The case of Spanish ceramic exports. Maritime Economics \& Logistics, v. 5, n. 2, p. 179-198, 2003.

MENTZER, J. T.; FLINT, D. J. Validity in logistics research. Journal of Business Logistics, v. 18, n. 1, p. 199-216, 1997.
MOSER, C., KALTON, G. Survey methods in social investigation. London: Heinemann Educational Books, 1971.

NÓRCIO, L.; PIMENTEL, C. Cai a fila de caminhões no porto de Paranaguá. Gazeta Mercantil, 15 abr. 2004.

PORTOS E NAVIOS. Greve prejudica desembarque em Suape. Disponível em: <www.portosenavios.com.br>. Acesso em: 15 abr. 2004.

RECEITA FEDERAL. Portos secos. Disponível em: <http://www.receita.fazenda.gov.br>. Acesso em: 28 jan. 2004.

RIOS, C. Vistoria de cargas nos portos será agilizada. Gazeta Mercantil, 9 mar. 2004a.

RIOS, C. Quebra de safra faz o frete ferroviário despencar no Paraná. Gazeta Mercantil, 11 mar. 2004b.

SAFATLE, C.; RIBAMAR, O. Empresas pagam por deficiência de portos. Valor Econômico, 14 mai. 2004.

SALES, A. O Brasil competitivo passa pelos portos. Revista Tecnologística, n. 69, 2001.

SOUZA, L. Portos estão perto do limite. Folha de S. Paulo, 7 jun. 2004.

TABACHNICK, B. G.; FIDELL, L. S. Using multivariate statistics. Boston: Allyn and Bacon, 2001.

TONGZON, J. The impact of wharfage costs on Victoria's export-oriented industries. Economic Papers, v. 8, p. 58-64, 1989. 
TORRES, C. L. Ineficiência logística afeta competitividade brasileira. Valor Econômico, 16 jul. 2004.

TORRES, C. L. Recursos para contornar gargalos nas ferrovias. Valor Econômico, 16 jul. 2004.

TRINDADE, R. Porto de Santos funcionará 24 horas. Valor Econômico, 5 mai. 2004.

WANKE, P. F.; FLEURY, P. F. Transporte de cargas no Brasil: estudo exploratório das principais variáveis relacionadas aos diferentes modais $\mathrm{e}$ às suas estruturas de custos. In: DE NEGRI, J. A.; KUBOTA, L. C. (Org.). Estrutura e Dinâmica do Setor de Serviços no Brasil. Brasília: IPEA, p. 409-464, 2006.

WANKE, P. F.; ARKADER, R.; HIJJAR, M. F. Logistics sophistication, manufacturing segments and the choice of logistics providers. International Journal of Operations \& Production Management, v. 27, p. 542-559, 2007.

WANKE, P. F; HIJJAR, M. F; BARROS, M. Avaliando a eficiência dos terminais brasilei- ros com Análise Envoltória de Dados. Revista Tecnologística, n. 4, p. 72-76, 2008.

WALTER, C. K.; POIST, R. F. North American inland port development: international vs. domestic shippers preferences. International Journal of Physical Distribution \& Logistics Management, v. 34, n. 7/8, p. 579-597, 2004.

WILSON, D.; PURUSHOTHAMAN, R. Dreaming with BRICs: The path to 2050. Global Economic Paper No: 99. Disponível em: <www.gs.com>. Acesso em: 15 set. 2003.

\section{SOBRE OS AUTORES}

\section{Peter Fernandes Wanke}

Instituto COPPEAD de Administração

Universidade Federal do Rio de Janeiro

Rua Paschoal Lemme, n. 355, 4ํandar - Ilha do Fundão - Rio de Janeiro - RJ - Brasil - 21949-900

Tel: +55 (21) 2598- 9812 Fax: +55 (21) 2270-3054

E-mail: peter@coppead.ufrj.br

\section{Maria Fernanda Hijjar}

Instituto COPPEAD de Administração

Universidade Federal do Rio de Janeiro

Rua Paschoal Lemme, n. 355, 4ํandar - Ilha do Fundão - Rio de Janeiro - RJ - Brasil - 21949-900

Tel: +55 (21) 2598- 9812 Fax: +55 (21) 2270-3054

E-mail: nanda@coppead.ufri.br 